\title{
Excretion of trazodone in breast milk
}

\author{
R. K. VERBEECK, S. G. ROSS \& E. A. McKENNA \\ Colleges of Pharmacy and Medicine, University of Saskatchewan, Saskatoon, Saskatchewan S7N OWO, \\ Canada.
}

The excretion of breast milk was studied in six lactating women following the oral administration of a single trazodone tablet $(50 \mathrm{mg})$. The milk/plasma ratio of trazodone based on area under the plasma and milk curves was small: $0.142 \pm 0.045$ (mean \pm s.d.).

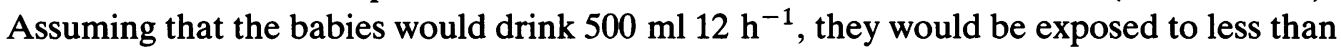
$0.005 \mathrm{mg} \mathrm{kg}^{-1}$ as compared to $0.77 \mathrm{mg} \mathrm{kg}^{-1}$ for the mothers. It is concluded that exposure of babies to trazodone via breast milk is very small.

Keywords trazodone pharmacokinetics breast milk nursing women

\section{Introduction}

Trazodone is a triazolopyridine derivative with antidepressant activity, that is unrelated to other currently available antidepressants (Brogden $e t$ al., 1981). It is extensively metabolized with only negligible amounts being excreted in urine as unchanged drug. The elimination half-life of trazodone between 10 to $34 \mathrm{~h}$ following oral dosing is approximately 6 to $12 \mathrm{~h}$ (Yamato et al., 1976; Bayer et al., 1983; Gammans et al., 1984).

Unlike the tricyclic antidepressants, trazodone does not exhibit anti-cholinergic side effects (Gershon \& Newton, 1980) and it may be useful in the treatment of postpartum depression. However, its use in nursing mothers is not recommended due to lack of information about its excretion in breast milk. Accordingly, the present study was undertaken to examine the transfer of trazodone into breast milk.

\section{Methods}

\section{Subjects}

Written, informed consent was obtained from six healthy lactating women between 3 and 8 months postpartum. The mean age of the women was 32.5 years (range: $30-37$ ) and mean weight was $64.9 \mathrm{~kg}$ (range: 56.7-68.0). The mean age of the babies was 4.8 months and their average weight was $6.7 \mathrm{~kg}$ (range: $5.4-9.1 \mathrm{~kg}$ ). None of the women was taking any medication for 2 weeks before the study. Women were instructed to refrain from nursing their infants during the first $4 \mathrm{~h}$ following drug administration.

\section{Study design}

After an overnight fast, each study subject was given a $50 \mathrm{mg}$ oral dose of trazodone. Food was not permitted until $3 \mathrm{~h}$ following drug administration. Venous blood samples were obtained in evacuated heparinized tubes immediately before drug administration and at 0.5 , $1,2,3,4,6,9,12,24$ and $30 \mathrm{~h}$. Blood samples were immediately centrifuged and plasma was kept frozen at $-20^{\circ} \mathrm{C}$ until analyzed. Milk samples $(5-10 \mathrm{ml})$ were collected from each breast by manual expression at the times of blood collection. The $\mathrm{pH}$ was measured immediately and the milk samples were kept frozen $\left(-20^{\circ} \mathrm{C}\right)$ pending analysis. The study was approved by the University Human Ethics Committee.

\section{Trazodone assay in plasma and milk}

The concentration of trazodone in plasma and breast milk was determined by high pressure liquid chromatography. To $0.1-1.0 \mathrm{ml}$ of plasma

Correspondence: Dr R. K. Verbeeck, College of Pharmacy, University of Saskatchewan, Saskatoon, Saskatchewan S7N OWO, Canada. 
or milk were added: $50 \mu$ internal standard stock solution $\left(2 \mu \mathrm{g}\right.$ diazepam $\left.\mathrm{ml}^{-1} 0.01 \mathrm{~N} \mathrm{HCl}\right)$, $0.5 \mathrm{ml}$ saturated (aqueous) sodium carbonate and double distilled water to a total volume of $2.5 \mathrm{ml}$. The mixture was extracted with $6 \mathrm{ml}$ isopropylalcohol: pentane (3:97, v/v). After centrifugation the organic phase was transferred to a clean tube and evaporated to dryness at $40^{\circ} \mathrm{C}$ under a gentle stream of nitrogen. The residue was dissolved in $100 \mu \mathrm{l}$ solvent system and $10 \mu \mathrm{l}$ was injected onto a Novapak $\mathrm{C}_{18}$ column (Waters Associates). The solvent system consisted of 39 parts methanol, 47 parts buffer (9.86 $\mathrm{g} \mathrm{NaH}_{2} \mathrm{PO}_{4}$ in 11 water) and 14 parts acetonitrile, adjusted to $\mathrm{pH} 6.5$ with $\mathrm{NaOH}$. The flow rate was $1.5 \mathrm{ml} \mathrm{min}^{-1}$ and trazodone and internal standard were detected by u.v. at $211 \mathrm{~nm}$.

\section{Pharmacokinetic analysis}

The plasma elimination half-life of trazodone $\left(t_{1 / 2, z}\right)$ was calculated by linear regression of the natural logarithm of plasma concentration $v s$ time from $4 \mathrm{~h}$ following drug administration on. Area under the plasma (milk) concentration vs time curve (AUC ${ }^{P}$ and $A U C^{M}$ ) was determined by trapezoidal rule. Total area under the plasma curve $\left(\mathrm{AUC}_{0-\infty}^{\mathrm{P}}\right)$ was obtained as follows:

$$
\mathrm{AUC}_{0-\infty}^{\mathrm{P}}=\mathrm{AUC}_{0-t^{*}}^{\mathrm{P}}+\frac{C_{t^{*}} t_{1 / 2, \mathrm{z}}}{0.693}
$$

where $t^{*}$ is the last sampling time and $C_{t^{*}}$ is the trazodone plasma concentration at the last sampling time. Total body clearance $\left(\mathrm{CL}_{\mathrm{b}} / F\right)$ of trazodone was calculated as follows:

$$
\mathrm{CL}_{\mathrm{b}} / F=\frac{D}{\mathrm{AUC}_{0-\infty}^{\mathrm{P}}}
$$

where $F$ is the oral availability of the trazodone tablet. The milk/plasma ratio of trazodone $(\mathrm{M} / \mathrm{P})$ was calculated as follows:

$$
\frac{M}{P}=\frac{\operatorname{AUC}_{0-t}^{M}}{\operatorname{AUC}_{0-t}^{P}}
$$

\section{Results}

No endogenous interfering peaks were present in the chromatograms for plasma or breast milk extracts. Retention times for trazodone and diazepam (internal standard) were approximately $5 \mathrm{~min}$ and $7 \mathrm{~min}$ respectively. Within sample coefficient of variation $(n=6)$ was low: $4.8 \%$ at

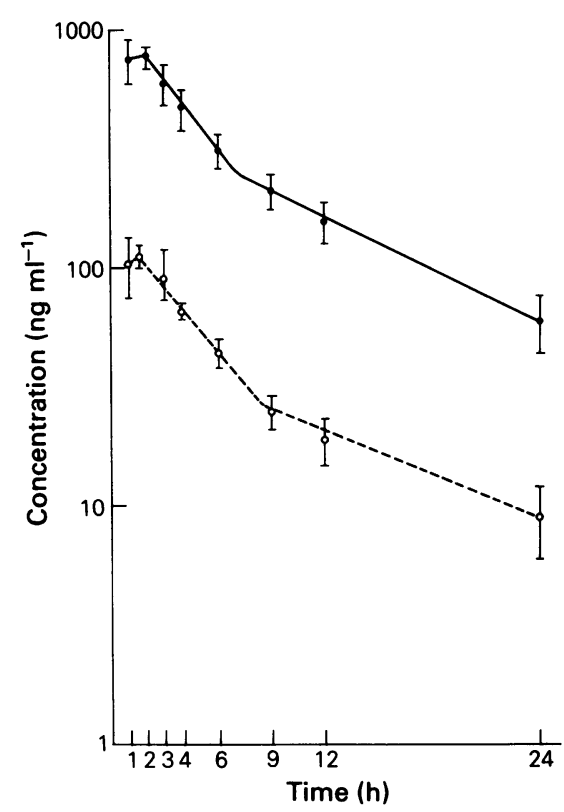

Figure 1 Mean \pm s.d. $(n=6)$ semi-logarithmic concentration-time profiles of trazodone in plasma $(\bullet-\bullet)$ and breast milk $(\circ-0)$ following a single $50 \mathrm{mg}$ trazodone dose.

$10 \mathrm{ng} \mathrm{ml}^{-1}$ and $2.9 \%$ at $250 \mathrm{ng} \mathrm{ml}^{-1}$. Day-to-day coefficient of variation in the slopes of the calibration curves was $8.4 \%$. Standard curves for trazodone in plasma and milk were linear over a concentration range of $10 \mathrm{ng} \mathrm{ml}^{-1}$ to $200 \mathrm{ng} \mathrm{ml}^{-1}$. The lower limit of detection was $10 \mathrm{ng} \mathrm{ml}^{-\mathrm{i}}$ plasma or milk.

Figure 1 shows the mean concentration-time profiles of trazodone in plasma and breast milk of the six mothers. Peak plasma concentrations were reached $2 \mathrm{~h}$ following ingestion of the trazodone tablet. From then on plasma concentrations declined bi-exponentially. Pharmacokinetic parameters of trazodone in the nursing mothers are summarized in Table 1 . The concentrations of trazodone in breast milk generally paralleled those in plasma (Figure 1) but were almost one order of magnitude lower. Milk/ plasma ratios calculated using equation 3 averaged $0.142 \pm 0.045$. The average $\mathrm{pH}$ of the breast milk samples was $7.19 \pm 0.08$ (range: 6.86-7.43).

\section{Discussion}

The pharmacokinetic parameters of trazodone following oral administration of a $50 \mathrm{mg}$ tablet to six nursing mothers were very similar to 
Table 1 Pharmacokinetic parameters of trazodone in lactating women and its excretion in breast milk

\begin{tabular}{ccccccc}
\hline Subject & $\begin{array}{c}\text { Age } \\
(\text { years })\end{array}$ & $\begin{array}{c}\text { Weight } \\
(\mathrm{kg})\end{array}$ & $\begin{array}{c}\mathrm{CL} / \mathrm{F} \\
\left(\mathrm{ml} \mathrm{min}^{-1}\right)\end{array}$ & $\begin{array}{c}\mathrm{t}_{1 / 2, \mathrm{z}} \\
(\mathrm{h})\end{array}$ & $\begin{array}{c}\mathrm{pH} \\
\text { milk*}\end{array}$ & $\begin{array}{c}\text { Milk/plasma } \\
\text { ratio }\end{array}$ \\
\hline 1 & 32 & 56.7 & 295.0 & 5.3 & 7.34 & 0.209 \\
2 & 37 & 68.0 & 165.2 & 6.3 & 7.11 & 0.183 \\
3 & 31 & 65.8 & 111.7 & 12.3 & 7.19 & 0.120 \\
4 & 33 & 66.0 & 115.2 & 6.7 & 7.18 & 0.125 \\
5 & 30 & 65.6 & 93.5 & 9.3 & 7.10 & 0.090 \\
6 & 32 & 67.1 & 193.7 & 5.2 & 7.13 & 0.125 \\
Mean & 32.5 & 64.9 & 162.4 & 7.5 & 7.19 & 0.142 \\
s.d. & 2.4 & 4.1 & 75.0 & 2.8 & 0.08 & 0.045 \\
\hline
\end{tabular}

*Mean $\mathrm{pH}$ value of all the breast milk samples collected in each subject.

values reported previously in healthy young volunteers (Bayer et al., 1983; Gammans et al., 1984; Yamato et al., 1976). Most reports have shown that trazodone exhibits a bi-exponential disposition curve in plasma with a terminal halflife of 6 to $12 \mathrm{~h}$ which is consistent with our findings (Bayer et al., 1983; Gammans et al., 1984; Yamato et al., 1976).

Transfer of drug in breast milk is dependent upon several factors (Welch \& Findlay, 1981; Wilson et al., 1980). First, only the fraction of drug not bound to plasma proteins is free to diffuse from plasma to other tissues and fluid compartments. In vitro plasma protein binding studies have shown that trazodone was 96,98 and $97 \%$ bound at concentrations of 1.0, 0.1 and $0.01 \mu \mathrm{g} \mathrm{ml}^{-1}$ respectively (personal communication, R. E. Gammans, Bristol-Myers Company, Evansville, IN). Second, the $\mathrm{pH}$ partition hypothesis assumes only the unionized species of the free drug is able to cross biological membranes. Because trazodone is a weak base with a pKa of 6.15, it is mostly in the unionized form in plasma ( $\mathrm{pH}$ 7.4). The theoretical milk/plasma ratio of trazodone may be calculated as follows (Wilson et al., 1980):

$$
\frac{\text { milk }}{\text { plasma }}=\frac{1+10^{\mathrm{pKa}-\mathrm{pH}(\text { milk })}}{1+10^{\mathrm{pKa}-\mathrm{pH}(\text { plasma })}} \cdot \frac{f_{\mathrm{P}}}{f_{\mathrm{M}}}
$$

where $f_{\mathrm{P}}$ and $f_{\mathrm{M}}$ are the free fractions of trazodone in plasma and milk respectively. Based on our findings of milk/plasma ratio and $\mathrm{pH}$ (milk) and assuming $f_{\mathrm{P}}=0.03$ we can calculate that $f_{M}$ is
0.22 . We did not measure the binding of trazodone to breast milk, but it has recently been reported that diazepam shows a binding to breast milk between 60 and $80 \%$ (Syversen \& Ratkje, 1985). These investigators found that lipid solubility of the drug and fat content of milk seem to be important factors determining the distribution of drug in breast milk.

Based on our results and assuming that the babies (mean age: 4.8 months) would have drunk $500 \mathrm{ml}$ milk during the $12 \mathrm{~h}$ following $50 \mathrm{mg}$ trazodone ingestion by their mothers (Whitehead \& Paul, 1981), the average amount of trazodone ingested by the babies was calculated to be approximately $0.03 \mathrm{mg}$ (Wilson et al., 1980 , equation 8 ). This means that on a weight basis the mothers received $0.77 \mathrm{mg} \mathrm{kg}^{-1}$ whereas the babies were exposed to less than $0.005 \mathrm{mg}$ $\mathrm{kg}^{-1}$. These calculations show that exposure of babies to trazodone via breast milk would be minimal with the baby's dose more than 150 times smaller than the maternal dose on a weight basis. However, trazodone has been reported to form an active metabolite, 1-m-chlorophenylpiperazine (Caccia et al., 1981) and it is not known to what extent this metabolite distributes into breast milk. The significance of this metabolite is unclear at this time since it has been demonstrated not to achieve appreciable plasma concentrations after single doses in man.

This study was supported by a Grant-In-Aid from Bristol-Myers Canada. The authors wish to thank Ms J. Huck for typing the manuscript.

\section{References}

Bayer, A. J., Pathy, M. S. J. \& Ankier, S. I. (1983). Pharmacokinetic and pharmacodynamic characteristics of trazodone in the elderly. Br. J. clin. Pharmac., 16, 371-376.
Brogden, R. N., Heel, R. C., Speight, T. M. \& Avery G. S. (1981). Trazodone: a review of its pharmacological properties and therapeutic use in depression and anxiety. Drugs, 21, 401-429. 
Caccia, S., Ballabio, M., Samanin, R., Zanini, M. G. \& Garattini, S. (1981). (-)-m-Chlorphenylpiperazine agonist, a central 5-hydroxytryptamine agonist is a metabolite of trazodone. J. Pharm. Pharmac., 33, 447-478.

Gammans, R. E., Machenthun, A. V. \& Russell, J. W. (1984). Comparative bioavailability of trazodone formulations using stable isotope methodology. Br. J. clin. Pharmac., 18, 431-437.

Gershon, S. \& Newton, R. (1980). Lack of anticholinergic effects with a new antidepressant-trazodone. J. clin. Psychiat., 41, 100-104.

Syversen, G. B. \& Ratkje, S. K. (1985). Drug distribution within human milk phases. J. pharm. Sci., 74, 1071-1074.

Welch, R. M. \& Findlay, J. W. A. (1981). Excretion of drugs in human breast milk. Drug Metab. Rev., 12, 261-277.
Whitehead, R. G. \& Paul, A. A. (1981). Infant growth and human milk requirements. Lancet, ii, 161-163. Wilson, J. T., Brown, R. D., Cherek, D. R., Daily, J. W., Hilman, B., Jobe, P. C., Manno, B. R., Manno, J. E., Redetski, H. M. \& Stewart, J. J. (1980). Drug excretion in human breast milk. Principles, pharmacokinetics and projected consequences. Clin. Pharmacokin., 5, 1-66.

Yamato, C., Takahashi, T. \& Fujita, T. (1976). Studies on metabolism of trazodone. III. Species differences. Xenobiotica, 6, 295-306.

(Received 13 January 1986, accepted 23 April 1986) 